\title{
Associations of physical activity and fruit and vegetable intake with well-being and depressive symptoms among obese schoolchildren in Wuhan, China: a cross- sectional study
}

Hong-jie $\mathrm{Yu}^{1 \dagger}$, Fang $\mathrm{Li}^{2 \dagger}$, Yong-feng $\mathrm{Hu}^{3}$, Chang-feng $\mathrm{Li}^{2}$, Xu-hao Yang ${ }^{1}$, Shuai Yuan ${ }^{1}$, Yao Huang ${ }^{1}$, Bo-wen Tang ${ }^{1}$, Jie Gong ${ }^{2^{*}}$ and Qi-qiang He $\mathrm{H}^{1^{*}}$

\begin{abstract}
Background: The prevalence of childhood obesity is increasing and psychological disorder is a common comorbidity of obesity. We investigated the associations of physical activity (PA) and fruit and vegetable (FV) intake with well-being and depressive symptoms among obese schoolchildren.

Methods: Participants included 188 obese children aged $9.8 \pm 0.7$ years living in Wuhan, China. Self-administered questionnaires were used to collect the children's PA and FV intake information. PA was considered to be high if the child participated in sport and/or vigorous free play at least 3 days per week with 60 min per day, while sufficient FV intake was defined as consuming FV 5 times per day. Children's well-being and depressive symptoms were assessed by standard questionnaires. Multiple logistic regression was performed to determine the odds ratios (ORs) and 95\% confidence intervals (Cls) of the relationships of PA and FV intake with well-being and depressive symptoms.

Results: High PA and sufficient FV intake were independently associated with significantly decreased risks for depressive symptoms (for PA, OR: 0.39, 95\% Cl: 0.16-0.92; for FV, OR: 0.21, 95\% Cl: 0.08-0.55) and poor well-being (for PA, OR: 0.35, 95\% Cl: 0.16-0.74), respectively. Furthermore, interactive inverse associations were observed between combined high PA and sufficient FV intake with poor well-being and depressive symptoms. Compared to their counterparts, children with high PA and sufficient FV intake had significantly reduced risk for poor well-being (OR: 0.16, 95\%Cl: 0.05-0.55) and depressive symptoms (OR: 0.12, 95\% Cl: 0.03-0.48).
\end{abstract}

Conclusions: High PA and sufficient FV intake are inversely associated with the risks of poor well-being and depressive symptoms among obese Chinese schoolchildren.

Keywords: Physical activity, Fruit and vegetable intake, Obesity, Children, Mental health

\footnotetext{
* Correspondence: gongjie322@163.com; heqiqiang@gmail.com

${ }^{\dagger}$ Hong-jie Yu and Fang Li contributed equally to this work.

${ }^{2}$ Wuhan Centers for Disease Prevention and Control, Hanbei Road 24\#,

Wuhan, People's Republic of China

'School of Health Sciences, Wuhan University, Donghu Road 185\#, Wuhan,

People's Republic of China

Full list of author information is available at the end of the article
}

(c) The Author(s). 2018 Open Access This article is distributed under the terms of the Creative Commons Attribution 4.0 International License (http://creativecommons.org/licenses/by/4.0/), which permits unrestricted use, distribution, and reproduction in any medium, provided you give appropriate credit to the original author(s) and the source, provide a link to the Creative Commons license, and indicate if changes were made. The Creative Commons Public Domain Dedication waiver (http://creativecommons.org/publicdomain/zero/1.0/) applies to the data made available in this article, unless otherwise stated. 


\section{Background}

The increasing prevalence of childhood obesity has become a serious public health problem worldwide $[1,2]$. A recent report by World Health Organization indicated that the global prevalence of overweight and obesity increased dramatically from 4\% in 1975 to over 18\% in 2016 among children and adolescents aged 5-19 years [3]. Likewise, results from a nationally representative sample of 40,780 US children and adolescents suggested that the prevalence of obesity among children aged 6 to 11 years increased from $11.3 \%$ in $1988-1994$ to $17.4 \%$ in 2012-2013 [4]. In China, rapid economic growth has resulted in an increased prevalence of obesity during the last few decades. Findings from a national survey between 1997 and 2011 showed that the prevalence of obesity in children aged 7-17 years more than doubled from 6.5 to $15.5 \%$ in boys and from 4.6 to $10.4 \%$ in girls [5].

Childhood obesity has been linked to increased metabolic and cardiovascular risks [6]. In addition, cumulative evidences indicate that mental disorder is a common comorbidity of obesity $[7,8]$. The prevalence of depressive symptoms in children and adolescents was approximate to $14 \%$ in China [9], and that in obese children and adolescents even reached to $23.62 \%$ [10]. Findings from a 2-year longitudinal study also suggested a significantly increased risk for poor well-being among overweight and obese children [11]. Given that obesity and obesity-related psychological comorbidities may continue from childhood into adulthood $[6,12]$, it is of importance to initiate early interventions to prevent obesity and reduce the risk of mental disorders in young children.

Unhealthy lifestyles including low physical activity (PA) and insufficient fruit/vegetable (FV) intake are very common among children and adolescents, and play a crucial role in the development of obesity [13]. Few studies have examined the association of PA and FV intake with mental health in general child population. The results from the Canadian Community Health Survey indicated that sufficient FV intake was associated with a $27 \%$ decrease in odds of depressive symptoms relative to control group [14]. A meta-analysis pooling 73 studies also demonstrated significant effects of PA on children's mental health [15]. However, it is unclear whether PA and FV intake are positively associated with mental health among Chinese children with obesity, although the relationships of these factors with physical health have been well documented [16, 17]. This information could be useful to develop interventions to inhibit the increasing prevalence of childhood obesity in China [18]. Therefore, the main objective of this study was to examine the associations of PA and FV intake with mental health in a sample of obese Chinese schoolchildren.

\section{Methods}

\section{Study design and participants}

This cross-sectional study was conducted in November 2015 in Wuhan, China. One district (Xinzhou district) was randomly selected from 13 districts in Wuhan city. Then two schools from 30 public primary schools in Xinzhou District were randomly recruited for this study. Sample size was calculated by the following equation: $n=z^{2} p(1-p) / d^{2}$, where $n=$ sample size, $z=z$ statistic corresponding to a chosen level of confidence (1.96), $p=$ expected prevalence $(0.13)$, and $d=$ precision $(0.05)$ [19], considering non-response rate of $5 \%$, this calculation resulted in a sample size of 183 obese children. Children in Grade 3rd and 4th in each school were invited to participate in a physical examination (height and weight measures). Of 1340 children (1051 boys), 203 obese children (152 boys) were identified using Chinese body mass index (BMI) cut-off points (Additional file 1: Table S1) [20]. Written informed consent was obtained from parents of the children. Only children who consented and obtained their parents' consent were included in this study. Children with a known chronic disease (such as diabetes, heart diseases, etc.) were excluded. This study was approved by the Medical Research Ethics Committee of Wuhan University.

\section{Measures}

Children completed a self-administered questionnaire in classrooms with the guidance of investigators who were trained medical graduate students from Wuhan University. The questionnaire contained information on their PA, FV intake, poor well-being and depression status. Parents were asked to report their household income using a short questionnaire.

\section{Physical activity}

Habitual PA was asked by the question - How often do you sport and/or vigorous free play (such as running, gymnastics, push-ups and jumping rope) each week with $60 \mathrm{~min}$ at least per day? Response options included: less than once per week, 1-2 days/week, 3-4 days/week, 56 days/week, and daily. This item was derived from the PA recommendation for children published by US Centers for Disease Control and Prevention [21], which was a valid instrument for examination of PA and basically consistent with PA guidelines for Chinese Children published by Working Group on Physical Activities Guidelines for Children and Adolescents in China [22]. Children with high PA were defined as those who participated in sports and/or vigorous free play at least three days per week for at least $60 \mathrm{~min}$ per day. 


\section{Fruit and vegetable intake}

FV intake was assessed by the question - During the past 30 days, how many times per day did you usually eat fruits/vegetables? There were seven possible options: I did not eat fruit/vegetables, less than once per day, once per day, 2 times per day, 3 times per day, 4 times per day, 5 or more times per day. The FV questionnaire was derived from Global School-based Student Health Survey, and its reliability and relative validity has been assessed among school-aged children in China. Children with sufficient FV intake were defined as those who consumed at least 5 times per day [23].

\section{Well-being}

Well-being was assessed by the WHO-5 well-being index (WHO-5), which is the most widely used questionnaire measuring subjective well-being, and its good reliability and validity have been shown in children [24]. The questionnaire consists of 5 positively worded items that reflect the presence or absence of well-being in the past 2 weeks: (1) I have felt cheerful and in good spirits, (2) I have felt calm and relaxed, (3) I have felt active and vigorous, (4) I woke up feeling fresh and rested, and (5) My daily life has been filled with things that interest me. Each item score ranges from 0 to 5 , and the sum scores is between 0 and 25. A total score $<13$ indicates poor well-being [24].

\section{Depressive symptoms}

Depressive symptom was evaluated using the Depression Self-rating Scale for Children (DSRSC). DSRSC has been widely used to assess depressive symptoms among children, and its reliability and validity have been examined in Chinese children [25]. It consists of 18 items utilizing a three-point scale response format including "never (score $=0)$ ", "sometimes (score $=1)$ " "most of the time (score $=2$ )", and the sum score is between 0 and 36 . Higher scores on the DSRSC indicate a higher level of depression, and a total score of 15 is set as a cut-off point of depressive disorders to divide participants into two groups (yes/no) [25].

\section{Statistical analysis}

Study children were divided into low (insufficient) and high (sufficient) groups in accordance with the PA level and FV intake, respectively. There was an interactive effect between PA, FV intake and the risk of psychological factors in the study children $(p<0.05)$. Each socioeconomic variable and BMI were initially checked separately with main model by psychological status, only statistical significant variables were entered in the final model as potential confounders (school, sex, age, BMI, and household income). Multiple logistic regression models were performed to examine the odds ratios
(ORs) and 95\% confidence intervals (CIs) of the independent and interactive relationships of $\mathrm{PA}$ and FV intake with poor well-being and depressive symptoms. Hosmer and Lemeshow test were applied to assess the goodness of fit and Nagelkerke $\mathrm{R}^{2}$ values was used to estimate the proportion of explained variance in the logistic regression models. Statistical analyses were conducted using the SPSS statistical package (version 13.0; SPSS Inc., Chicago, IL. USA).

\section{Results}

A total of 188 obese children was included in the present study, including 42 (22.3\%) girls and 146 (77.7\%) boys. Table 1 displays the basic characteristics of participants with an age of 9.8 years (standard deviation, $\mathrm{SD}=$ 0.7). Children who reported high PA and sufficient FV intake accounted for 36.7 and $45.7 \%$, respectively. Forty three $(22.9 \%)$ children were identified with poor well-being, and 46 (24.5\%) children had depressive symptoms.

The independent associations of PA and FV intake with well-being and depressive symptoms are shown in Table 2. After adjustment for several potential confounders, high PA was associated with significantly reduced risks for depressive symptoms (OR: 0.39, 95\% CI: $0.16-0.92, p<0.05)$ and poor well-being (OR: 0.35 , 95\% CI: $0.16-0.74, p<0.01)$, respectively. Sufficient FV intake was associated with $79 \%$ reduction (OR: $0.21,95 \%$ CI: $0.08-0.55, p<0.01)$ in the risk of depressive symptoms,

Table 1 Basic characteristics of participants

\begin{tabular}{ll}
\hline Characteristics & \\
\hline Age (years), mean, SD & $9.8(0.7)$ \\
Sex-girls, \% & 22.3 \\
Height (cm), mean, SD & $144.8(5.9)$ \\
Weight (kg), mean, SD & $51.0(7.1)$ \\
BMI (kg/m²), mean, SD & $24.3(2.2)$ \\
Monthly household income, \% & \\
$\quad$ Low(< 5000 Yuan RMB) & 38.8 \\
$\quad$ Middle(5001-10,000 Yuan RMB) & 37.8 \\
$\quad$ High(> 10,000 Yuan RMB) & 14.4 \\
Physical activity, \% & \\
$\quad$ High & 36.7 \\
$\quad$ Low & 63.3 \\
Fruit and vegetable intake, \% & \\
$\quad$ Sufficient & \\
Insufficient & 45.7 \\
Poor well-being, \% & 54.3 \\
Depressive symptoms, \% & 22.9 \\
\hline
\end{tabular}

BMI body mass index, Yuan RMB unit of Chinese money, SD standard deviation Data are presented as mean (SD) or percentage, where appropriate 
Table 2 Associations between physical activity, fruit/vegetable intake and well-being, depressive symptoms among Participants

\begin{tabular}{|c|c|c|c|c|c|c|}
\hline \multirow[t]{2}{*}{ Characteristics } & \multicolumn{2}{|c|}{ Depressive symptoms } & \multirow[t]{2}{*}{$p$-value } & \multicolumn{2}{|c|}{ Poor well-being } & \multirow[t]{2}{*}{$p$-value } \\
\hline & N (\%) & OR $(95 \% \mathrm{Cl})$ & & $\mathrm{N}(\%)$ & OR $(95 \% \mathrm{Cl})$ & \\
\hline \multicolumn{7}{|c|}{ Physical activity $^{\mathrm{a}}$} \\
\hline Low & $33(17.5)$ & 1.00 & & $36(19.1)$ & 1.00 & \\
\hline High & $10(5.32)$ & $0.39(0.16-0.92)$ & 0.031 & $10(5.3)$ & $0.35(0.16-0.74)$ & 0.006 \\
\hline \multicolumn{7}{|c|}{ Fruit and vegetable intake ${ }^{b}$} \\
\hline Insufficient & $26(13.8)$ & 1.00 & & $24(12.8)$ & 1.00 & \\
\hline Sufficient & $17(9.0)$ & $0.21(0.08-0.55)$ & $<0.001$ & $22(11.7)$ & $0.57(0.28-1.18)$ & 0.130 \\
\hline
\end{tabular}

Abbreviation: $O R$ odd ratio, $\mathrm{Cl}$ confidence interval

Adjusted for school, sex, age, BMl, and household income

${ }^{\mathrm{a}}$ For depressive symptoms: Hosmer and Lemeshow Test: $\mathrm{Chi}^{2}=6.42, p=0.601$, Nagelkerke $\mathrm{R}^{2}=0.284$

${ }^{\mathrm{b}}$ For depressive symptoms: Hosmer and Lemeshow Test: $\mathrm{Chi}^{2}=7.74, p=0.460$, Nagelkerke $\mathrm{R}^{2}=0.273$

${ }^{\mathrm{a}}$ For poor well-being: Hosmer and Lemeshow Test: $\mathrm{Chi}^{2}=5.45, p=0.709$, Nagelkerke $\mathrm{R}^{2}=0.403$

${ }^{b}$ For poor well-being: Hosmer and Lemeshow Test: $\mathrm{Chi}^{2}=4.88, p=0.770$, Nagelkerke $\mathrm{R}^{2}=0.382$

while the association between FV intake and poor well-being was statistically insignificant.

Table 3 shows the interactive effects of PA and FV intake with well-being and depressive symptoms. Compared with those who had low PA and insufficient FV intake, children with high PA/insufficient FV had 79 and $73 \%$ lower risk of poor well-being and depressive symptoms (all $p<0.05)$, respectively, while children with high $\mathrm{PA} /$ sufficient $\mathrm{FV}$ had the lowest risk for poor well-being (OR: 0.16, 95\% CI: 0.05-0.55, $p<0.01$ ) and depressive symptoms (OR: $0.12,95 \%$ CI: $0.03-0.48, p<0.01$ ). The total explained variance for depressive symptoms and poor well-being, according to Nagelkerke $R^{2}$, was 29.0 and $40.4 \%$, respectively.

\section{Discussion}

Results from this study indicated that PA and FV intake were independently associated with reduced risk of poor well-being and depression among obese Chinese schoolchildren. Furthermore, obese children with high PA and sufficient FV intake had over $80 \%$ lower odds of poor well-being and depressive symptoms compared with those with low PA and low FV intake.

Previous studies revealed a relatively higher prevalence of psychological problems among obese children compared with that of this study. For example, in a sample of 102 adolescent patients from a weight management clinic, 34\% had depressive symptoms and 32\% had symptoms of anxiety [26]. A cross-sectional study in Canada found that depressive symptoms were common (36.4\%) in youth with obesity [27]. A systematic review of nine studies summarized that childhood obesity was related to several mental health disorders, including depression, low self-esteem and poor health-related quality of life among Australian children [28]. Two prospective cohort studies also found that adolescent obesity or overweight predicted subsequent depression and/ or anxiety in adulthood $[29,30]$. Therefore, in the design of effective approaches for preventing and treating obesity, it is of importance to consider whether adequate PA and sufficient FV intake can also improve psychological problems in obese children.

Previous investigations revealed that low PA and insufficient FV intake were very common among obese children. In the present study, a high percentage of children did not meet the recommendations for PA (63.3\%) and FV intake (54.3\%). Furthermore, we found that low PA and insufficient FV intake had a strong relationship with poor well-being and depressive symptoms. Although some studies reported no significant association between PA/FV and mental health among children and adolescents [31, 32], our results were generally in accordance

Table 3 Multiple logistic regression for well-being and depressive symptoms by combined physical activity and fruit/vegetable intake

\begin{tabular}{|c|c|c|c|c|c|c|c|}
\hline \multirow[t]{2}{*}{ Mental health } & \multirow{2}{*}{$\begin{array}{l}\text { Fruit and } \\
\text { vegetable } \\
\text { intake }\end{array}$} & \multicolumn{2}{|c|}{ Low physical activity } & \multirow[t]{2}{*}{$p$-value } & \multicolumn{2}{|c|}{ High physical activity } & \multirow[t]{2}{*}{$p$-value } \\
\hline & & N (\%) & OR $(95 \% \mathrm{Cl})$ & & N (\%) & OR $(95 \% \mathrm{Cl})$ & \\
\hline \multirow[t]{2}{*}{ Depressive symptoms $^{a}$} & Insufficient & $21(11.2)$ & 1.00 & & $5(2.7)$ & $0.21(0.06-0.77)$ & 0.019 \\
\hline & Sufficient & $12(6.4)$ & $0.57(0.24-1.32)$ & 0.185 & $5(2.7)$ & $0.12(0.03-0.48)$ & 0.003 \\
\hline \multirow[t]{2}{*}{ Poor well-being ${ }^{b}$} & Insufficient & $19(10.1)$ & 1.00 & & $5(2.7)$ & $0.27(0.08-0.88)$ & 0.028 \\
\hline & Sufficient & $17(9.0)$ & $0.27(0.11-0.68)$ & 0.005 & $5(2.7)$ & $0.16(0.05-0.55)$ & 0.003 \\
\hline
\end{tabular}

OR odd ratio, $\mathrm{Cl}$ confidence interval

Adjusted for school, sex, age, BMI, and household income

${ }^{\mathrm{a}}$ For depressive symptoms: Hosmer and Lemeshow Test: $\mathrm{Chi}^{2}=5.98, p=0.650$, Nagelkerke $\mathrm{R}^{2}=0.290$

${ }^{\mathrm{b}}$ For poor well-being: Hosmer and Lemeshow Test: $\mathrm{Chi}^{2}=7.10, p=0.526$, Nagelkerke $\mathrm{R}^{2}=0.404$ 
with most previous epidemiological studies [33, 34]. For example, a follow-up study found that PA might be more beneficial for mental functioning among those with overweight than normal weight individuals [33]. Evidence from a Canadian national survey also suggested that the consumption of FV played an important role in the prevention of mental disorders [35]. These findings suggest that high PA and sufficient FV intake recommendation should be integrated into mental health prevention strategies to reduce the risk of psychological problems among children.

Although healthy lifestyle behaviors have been associated with better cardiovascular and metabolic health [36], their joint associations with mental health have been little studied. In a recent cohort study, combined effects of PA and healthy dietary patterns on metabolic syndrome were observed among Chinese adults [37]. Nevertheless, the joint relationship of PA and FV intake with obese children's mental health remained unclear. The present study not only shows an independent favorable influence of PA and FV intake, but also reveals a combined association of high PA and FV intake with reduced risk of poor well-being and depressive symptoms among obese Chinese children. Thus, our results add further evidence for future prevention and health promotion strategies integrating PA and FV consumption to promote mental health among obese children.

The exact mechanisms of synthetic effects of PA and FV on mental health have yet to be fully elucidated. Exercise can stimulate the growth of new nerve cells and the induction of the release of proteins and peptides that promote the sense of well-being [38]. Meanwhile, FV are abundant in micronutrients and phytochemicals which may not only mediate anti-oxidative and anti-inflammatory activities [39], but also improve the release of serotonin in the brain [14]. In addition, dietary factors may exert their effects on brain through influencing molecular events associated with cell and energy metabolism, which affects neuronal function and signaling, thus modulating mental health [40]. In terms of behavioral level, the latest research performed by Lena et al. reported that physical activity and nutrition appeared to facilitate rather than hindered each other among participants, and there was a "facilitating pattern" between PA and FV intake [41]. Since both PA and FV intake have been proven to improve psychological well-being through several pathways, it is biologically plausible that the combination of high PA and sufficient FV intake may contribute a better mental health.

The present study has several limitations. First, given that the cross-sectional study design cannot infer the causality of PA and FV intake with poor well-being and depressive symptoms, PA and FV intake may be a result of the nutritional and psychological status of the children and not the opposite. Second, international standardized questionnaires have been used to assess mental health. However, these measures were not equivalent to clinical diagnoses. Third, the FV questionnaire is a crude measure of food consumption. The items focused on frequency rather than portion size, and the questionnaire has not been validated in children. Nevertheless, it is simple and convenient to complete, and has been previously used among Chinese children [42]. Fourth, PA levels were self-reported by children, and thus recall and reporting bias might exist. Furthermore, we did not specify vigorous-intensity PA and moderate-intensity PA in the questionnaire. However, the aim of this study was to compare high PA with low PA, rather than PA intensity, on the risk of mental health. In addition, self-report PA has been widely used in epidemiological studies [43, 44]. The question for PA was similar to several previous studies that we conducted among Chinese schoolchildren [45, 46]. In addition, PA recalls are reliable estimate of PA in research among young children [47]. Fifth, although the reliability and validity of WHO-5 well-being index have been examined in western pediatric population, there is a lack of similar research in Chinese children. Thus, potential bias cannot be excluded. Last, only two schools from one district were included in this study, and there was a wide difference in the numbers of male and female participants. Therefore, caution should be made when generalizing our findings to national or international levels given the exclusive geographic location of this study.

\section{Conclusions}

In summary, results from the present study suggested that high PA and sufficient FV intake were inversely associated with poor well-being and depressive symptoms among Chinese obese children and showed additive associations. Our study provides further support for the key role of PA and FV intake in the prevention of mental disorders among obese children.

\section{Additional file}

Additional file 1: Table S1. Cut-off points of body mass index for obese children aged 8-12 years in China. (DOC $30 \mathrm{~kb}$ )

\section{Abbreviations}

BMI: Body mass index; Cl: Confidence interval; DSRSC: Depression self-rating scale for children; FV: Fruit and vegetable; OR: Odds ratio; PA: Physical activity; SD: Standard deviation

\section{Acknowledgements}

We thank the students, parents, school teachers, and field investigators who participated in this study. 


\section{Funding}

Financial support for this project was provided by The National Natural Science Foundation of China (No. 81372973).

\section{Availability of data and materials}

The baseline data used and analysed during the current study is available from the corresponding author on reasonable request.

\section{Authors' contributions}

Study concept and design: Yu HJ, Li F and He QQ. Acquisition of data: Yu HJ, Hu YF, Li CF, Yuan S, Huang Y, Tang BW and He QQ. Analysis and interpretation of data: $Y u H J$ and Yang XH. Drafting of the manuscript: $Y u H J$, $\mathrm{Li} F$ and $\mathrm{He} \mathrm{QQ}$. Critical revision of the manuscript for important intellectual content: Yu HJ, Gong J and He QQ. Study supervision: Gong J and He QQ. All authors read and approved the final manuscript.

\section{Ethics approval and consent to participate}

Written informed consent was obtained from parents of the children. This study was approved by the Medical Research Ethics Committee of Wuhan University.

\section{Consent for publication}

Not applicable.

\section{Competing interests}

The authors declare that they have no competing interests.

\section{Publisher's Note}

Springer Nature remains neutral with regard to jurisdictional claims in published maps and institutional affiliations.

\section{Author details}

'School of Health Sciences, Wuhan University, Donghu Road 185\#, Wuhan, People's Republic of China. ${ }^{2}$ Wuhan Centers for Disease Prevention and Control, Hanbei Road 24\#, Wuhan, People's Republic of China. ${ }^{3}$ Xinzhou Centers for Disease Prevention and Control, Wuhan, People's Republic of China.

Received: 1 November 2017 Accepted: 28 June 2018

Published online: 08 August 2018

\section{References}

1. de Onis M, Blossner M, Borghi E. Global prevalence and trends of overweight and obesity among preschool children. Am J Clin Nutr. 2010; https://doi.org/10.3945/ajcn.2010.29786.

2. Ng M, Fleming T, Robinson M, Thomson B, Graetz N, Margono C, et al. Global, regional, and national prevalence of overweight and obesity in children and adults during 1980-2013: a systematic analysis for the global burden of disease study 2013. Lancet. 2014; https://doi.org/10.1016/S01406736(14)60460-8.

3. World Health Organization. Overweight and obesity. http://www.who.int/ mediacentre/factsheets/fs311/en/. 20 February 2018.

4. Ogden $\mathrm{CL}$, Carroll MD, Lawman HG, Fryar CD, Kruszon-Moran D, Kit BK, et al. Trends in obesity prevalence among children and adolescents in the United States, 1988-1994 through 2013-2014. JAMA. 2016; https://doi.org/10.1001/ jama.2016.6361.

5. Wang $H$, Xue $H$, Du S, Zhang J, Wang $Y$, Zhang B. Time trends and factors in body mass index and obesity among children in China: 1997-2011. Int J Obesity. 2017; https://doi.org/10.1038/ijo.2017.53.

6. Faienza MF, Wang DQH, Fruhbeck G, Garruti G, Portincasa P. The dangerous link between childhood and adulthood predictors of obesity and metabolic syndrome. Intern Emerg Med. 2016; https://doi.org/10.1007/s11739-015-1382-6.

7. Morrison KM, Shin S, Tarnopolsky M, Taylor VH. Association of depression \& health related quality of life with body composition in children and youth with obesity. J Affect Disorders. 2015; https://doi.org/10.1016/j.jad.2014.09.014.

8. Lee E-Y, Spence JC. Pubertal development and screen time among South Korean adolescents: testing body mass index and psychological well-being as mediators. Glob Health Res Policy. 2016; https://doi.org/10.1186/s41256016-0019-2.
9. Zhou M, Zhang G, Rozelle S, Kenny K, Xue H. Depressive symptoms of Chinese children: prevalence and correlated factors among subgroups. Int Environ Res Public Health. 2018; https://doi.org/10.3390/ijerph15020283.

10. Zhang L, Liu K, Li H, Li D, Chen Z, Zhang LL, et al. Relationship between body mass index and depressive symptoms: the "fat and jolly" hypothesis for the middle-aged and elderly in China. BMC Public Health. 2016; https:// doi.org/10.1186/s12889-016-3864-5.

11. Hunsberger M, Lehtinen-Jacks S, Mehlig K, Gwozdz W, Russo P, Michels N, et al. Bidirectional associations between psychosocial well-being and body mass index in European children: longitudinal findings from the IDEFICS study. BMC Public Health. 2016; https://doi.org/10.1186/S12889-016-3626-4.

12. Goodwin RD, Sourander A, Duarte CS, Niemela S, Multimaki P, Nikolakaros $\mathrm{G}$, et al. Do mental health problems in childhood predict chronic physical conditions among males in early adulthood? Evidence from a communitybased prospective study. Psychol Med. 2009; https://doi.org/10.1017/ S0033291708003504

13. Daly CM, Foote SJ, Wadsworth DD. Physical activity, sedentary behavior, fruit and vegetable consumption and access: what influences obesity in rural children? J Commun Health. 2017; https://doi.org/10.1007/s10900-017-0343-6.

14. McMartin SE, Jacka FN, Colman I. The association between fruit and vegetable consumption and mental health disorders: evidence from five waves of a national survey of Canadians. Prev Med. 2013; https://doi.org/10. 1016/j.ypmed.2012.12.016.

15. Ahn S, Fedewa AL. A meta-analysis of the relationship between children's physical activity and mental health. J Pediatr Psychol. 2011; https://doi.org/ 10.1093/jpepsy/jsq107.

16. Whooten RC, Perkins ME, Gerber MW, Taveras EM. Effects of before-school physical activity on obesity prevention and wellness. Am J Prev Med. 2018; https://doi.org/10.1016/j.amepre.2018.01.017.

17. Bourke M, Whittaker PJ, Verma A. Are dietary interventions effective at increasing fruit and vegetable consumption among overweight children? A systematic review. J Epidemiol Commun H. 2014; https://doi.org/10.1136/ jech-2013-203238

18. Ji CY, Chen TJ, WGOC. Empirical changes in the prevalence of overweight and obesity among Chinese students from 1985 to 2010 and corresponding preventive strategies. Biomed Environ Sci. 2013; https://doi.org/10.3967/ 0895-3988.2013.01.001.

19. Daniel WW. Biostatistics: a Foundation for Analysis in the health sciences. New York: John Wiley \& Sons, Incorporated; 1998. p. 7.

20. Ji CY. Working group on obesity in China: report on childhood obesity in China (1)-body mass index reference for screening overweight and obesity in Chinese school-age children. Biomed Environ Sci. 2005;18(6):390-400.

21. National Center for Chronic Disease Prevention and Health Promotion. How much physical activity do children need? https://www.cdc.gov/ physicalactivity/basics/children/index.htm. 20 February 2018.

22. Zhang YT, SX MA, Cheng C, Liu SJ, Zhang CF, Cao ZB, et al. Physical activity guidelines for Chinese children and adolescents. Chin J Evid Based Pediatr. 2017; 10.369/j.issn.1673-5501.2017.06.001

23. Darfour-Oduro SA, Buchner DM, Andrade JE, Grigsby-Toussaint DS. A comparative study of fruit and vegetable consumption and physical activity among adolescents in 49 low-and-middle-income countries. Sci Rep-Uk 2018; https://doi.org/10.1038/S41598-018-19956-0.

24. Allgaier AK, Pietsch K, Fruhe B, Prast E, Sigl-Glockner J, Schulte-Korne G Depression in pediatric care: is the WHO-five well-being index a valid screening instrument for children and adolescents? Gen Hosp Psychiat. 2012; https://doi.org/10.1016/j.genhosppsych.2012.01.007.

25. Su LY, Wang K, Zhu Y, Luo XR, Yang ZW. Norm of the depression self-rating scale for children in Chinese urban children. Chin Ment Health J. 2003; https://doi.org/10.3321/j.issn:1000-6729.2003.08.011.

26. Fox CK, Gross AC, Rudser KD, Foy AM, Kelly AS. Depression, anxiety, and severity of obesity in adolescents: is emotional eating the link? Clin Pediatr (Phila). 2016; https://doi.org/10.1177/0009922815615825.

27. Goldfield GS, Moore C, Henderson K, Buchholz A, Obeid N, Flament MF. Body dissatisfaction, dietary restraint, depression, and weight status in adolescents. J Sch Health. 2010; https://doi.org/10.1111/j.1746-1561.2009.00485.x.

28. Sanders RH, Han A, Baker JS, Cobley S. Childhood obesity and its physical and psychological co-morbidities: a systematic review of Australian children and adolescents. Eur J Pediatr. 2015; https://doi.org/ 10.1007/s00431-015-2551-3.

29. Anderson SE, Cohen P, Naumova EN, Jacques PF, Must A. Adolescent obesity and risk for subsequent major depressive disorder and anxiety 
disorder: prospective evidence. Psychosom Med. 2007; https://doi.org/10. 1097/PSY.0b013e31815580b4.

30. Al Mamun A, Cramb S, McDermott BM, O'Callaghan M, Najman JM, Williams GM. Adolescents' perceived weight associated with depression in young adulthood: a longitudinal study. Obesity. 2007; https://doi.org/10.1038/oby. 2007.369.

31. Van Dijk ML, Savelberg H, Verboon P, Kirschner PA, De Groot RHM. Decline in physical activity during adolescence is not associated with changes in mental health. BMC Public Health. 2016; https://doi.org/10.1186/s12889-0162983-3.

32. Clark C, Haines MM, Head J, Klineberg E, Arephin M, Viner R, et al. Psychological symptoms and physical health and health behaviours in adolescents: a prospective 2-year study in East London. Addiction. 2007: https://doi.org/10.1111/j.1360-0443.2006.01621.x.

33. Lindhom V, Lahti J, Rahkonen O, Lahelma E, Lallukka T. Joint association of physical activity and body weight with subsequent physical and mental functioning: a follow-up study. BMC Public Health. 2013; https://doi.org/10. 1186/1471-2458-13-197.

34. Banta JE, Khoie-Mayer RN, Somaiya CK, McKinney O, Segovia-Siapco G. Mental health and food consumption among California children 5-11 years of age. Nutr Health. 2013; https://doi.org/10.1177/0260106015599511.

35. Kingsbury M, Dupuis G, Jacka F, Roy-Gagnon MH, McMartin SE, Colman I. Associations between fruit and vegetable consumption and depressive symptoms: evidence from a national Canadian longitudinal survey. J Epidemiol Community Health. 2016;70(2):155-61. https://doi.org/10.1136/ jech-2015-205858.

36. Van Buren DJ, Tibbs TL. Lifestyle interventions to reduce diabetes and cardiovascular disease risk among children. Curr Diab Rep. 2014; https://doi. org/10.1007/s11892-014-0557-2.

37. He Y, Li Y, Lai J, Wang D, Zhang J, Fu P, et al. Dietary patterns as compared with physical activity in relation to metabolic syndrome among Chinese adults. Nutr Metab Cardiovas. 2013; https://doi.org/10.1016/j.numecd.2012.09.001.

38. Helmich I, Latini A, Sigwalt A, Carta MG, Machado S, Velasques B, et al. Neurobiological alterations induced by exercise and their impact on depressive disorders. Clinical practice and epidemiology in mental health. CP EMH. 2010; https://doi.org/10.2174/1745017901006010115.

39. Rink SM, Mendola P, Mumford SL, Poudrier JK, Browne RW, WactawskiWende J, et al. Self-report of fruit and vegetable intake that meets the $5 \mathrm{a}$ day recommendation is associated with reduced levels of oxidative stress biomarkers and increased levels of antioxidant defense in premenopausal women. J Acad Nutr Diet. 2013; https://doi.org/10.1016/j.jand.2013.01.019.

40. Gomez-Pinilla F, Tyagi E. Diet and cognition: interplay between cell metabolism and neuronal plasticity. Curr Opin Clin Nutr. 2013; https://doi. org/10.1097/MCO.0b013e328365aae3.

41. Fleig L, Kuper C, Lippke S, Schwarzer R, Wiedemann AU. Cross-behavior associations and multiple health behavior change: a longitudinal study on physical activity and fruit and vegetable intake. J Health Psychol. 2015; https://doi.org/10.1177/1359105315574951.

42. He QQ, Wong TW, Du L, Lin GZ, Gao Y, Jiang ZQ, et al. Nutrition and children's respiratory health in Guangzhou, China. Public Health. 2008; https://doi.org/10.1016/j.puhe.2008.06.010.

43. Sprengeler O, Wirsik N, Hebestreit A, Herrmann D, Ahrens W. Domainspecific self-reported and objectively measured physical activity in children. Int J Environ Res Public Health. 2017; https://doi.org/10.3390/ ijerph14030242.

44. Moore HJ, Hillier FC, Batterham AM, Ells LJ, Summerbell CD. Technologybased dietary assessment: development of the synchronised nutrition and activity program (SNAP). J Hum Nutr Diet. 2014; https://doi.org/10.1111/j. 1365-277X.2012.01295.X.

45. Ji J, Wang SQ, Liu YJ, He QQ. Physical activity and lung function growth in a cohort of Chinese school children: a prospective study. PLoS One. 2013; https://doi.org/10.1371/journal.pone.0066098.

46. He QQ, Wong TW, Du L, Jiang ZQ, Yu TSI, Qiu H, et al. Physical activity, cardiorespiratory fitness, and obesity among Chinese children. Prev Med. 2011; https://doi.org/10.1016/j.ypmed.2010.11.005.

47. Strugnell C, Renzaho A, Ridley K, Burns C. Reliability of the modified child and adolescent physical activity and nutrition survey, physical activity (CAPANS-PA) questionnaire among Chinese-Australian youth. BMC Med Res Methodol. 2011; https://doi.org/10.1186/1471-2288-11-122.

\section{Ready to submit your research? Choose BMC and benefit from:}

- fast, convenient online submission

- thorough peer review by experienced researchers in your field

- rapid publication on acceptance

- support for research data, including large and complex data types

- gold Open Access which fosters wider collaboration and increased citations

- maximum visibility for your research: over $100 \mathrm{M}$ website views per year

At BMC, research is always in progress.

Learn more biomedcentral.com/submissions 